\title{
Prediksi Harga Rumah Menggunakan General Regression Neural Network
}

\author{
Evi Febrion Rahayuningtyas ${ }^{1}$, Feny Novia Rahayu ${ }^{2}$, Yufis Azhar ${ }^{3}$ \\ 1,2,3 Informatika, Fakultas Teknik, Universitas Muhammadiyah Malang \\ Jln. Raya Tlogomas No. 246 Tlogomas, Kec. Lowokwaru, Kota Malang, Indonesia
}

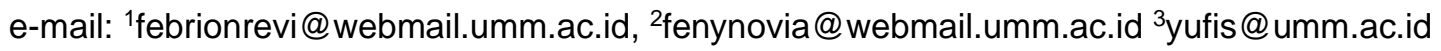

\begin{tabular}{llll}
\hline Informasi Artikel Diterima: 11-11-2020 & Direvisi: 13-11-2020 & Disetujui: 30-11-2020 \\
\hline
\end{tabular}

\begin{abstract}
Abstrak
Rumah merupakan salah satu kebutuhan manusia selain sandang dan pangan. Hirarki Kebutuhan Maslow menyebutkan bahwa rumah adalah salah satu Physiological Needs. Dewasa ini, kebutuhan akan rumah sering dijadikan sebagai sumber investasi bagi pengusaha properti yang tentunya menghasilkan investasi yang tidak dapat diremehkan. Keuntungan dalam jual beli rumah dijadikan alasan bagi seseorang dalam melakukan transaksi jual beli rumah itu sendiri. Sehingga munculah harga yang tidak terprediksi pada harga rumah yang ada. Penelitian ini menggunakan General Regression Neural Network sebagai pemodelannya. GRNN menggunakan dasar regresi non linear dimana strukturnya terdiri dari 4 layer, yaitu Input Layer, Pattern Layer, Summation Layer dan Output Layer. Variabel dependen yang digunakan berjumlah 6 . Terdiri dari tanggal transaksi, jarak rumah dari stasiun MRT, jumlah toko atau minimarket yang dekat dengan rumah, umur rumah, dan letak geografis berupa longitude dan latitude. Variabel independen berupa harga rumah dalam satuan luas Ping yang selanjutnya dikonversi menjadi 10.000 New Dollar Taiwan/Ping. Hasil yang didapatkan berupa data actual dan data predicted yang divisualisasikan dengan line plot. Dilakukan juga uji akurasi dan uji kinerja pemodelan menggunakan 3 jenis evaluasi dengan hasil dari ketiga jenis evaluasi tersebut adalah 58,72 untuk skor MSE, skor 7,66 untuk RMSE dan 5,99 untuk skor MAE.
\end{abstract}

Kata kunci: general regression neural network, prediksi, harga rumah

\begin{abstract}
House is one of the human needs in addition to clothing and food. Maslow's Hierarchy of Needs states that house is one of the Physiological Needs. Today, the need for housing is often used as a source of investment for property entrepreneurs, which certainly produces investments that can't be underestimated. The advantage in buying and selling a house is used as an excuse for someone in buying and selling a house itself. So there is an unpredictable price on the price of existing houses. This research used the General Regression Neural Network as the modeling. GRNN uses the basis of non-linear regression where the structure consists of 4 layers, namely the Input Layer, Pattern Layer, Summation Layer and Output Layer. The dependent variable used amounts to 6. Consists of transaction date, distance of the house from the MRT station, number of convenience stores in the living circle on foot, age of house, and geographical location in the form of longitude and latitude. The independent variable was the price of the house in units of Ping area which is then converted to 10,000 New Taiwan Dollars/Ping. The results obtained in the form of actual data and predicted data visualized by line plot. Accuracy tests and modeling performance tests were also performed using 3 types of evaluations with the results of the three types of evaluations being 58.72 for MSE score, 7.66 score for RMSE and 5.99 for MAE score.
\end{abstract}

Keywords: general regression neural network, prediction, house price

\section{Pendahuluan}

Rumah merupakan salah satu kebutuhan pokok manusia(Mahendra \& Putri,
2019), disamping kebutuhan sandang dan pangan rumah berfungsi pula sebagai tempat tinggal serta digunakan untuk berlindung dari 
gangguan iklim dan makhluk hidup lainnya. Rumah merupakan salah satu bangunan tempat tinggal yang harus memenuhi kriteria kenyamanan, keamanan dan kesehatan guna mendukung penghuninya agar dapat bekerja dengan produktif dan dapat menggunakan sebagai tempat tinggal yang sehat dan aman bagi penghuninya(Chamid, 2016). Hirarki Kebutuhan Maslow menyebutkan jika Rumah atau Papan adalah satu hal penting yang dikategorikan dalam Kebutuhan Fisiologis atau Physiological Needs manusia (Utamaningsih, Monika \& Yenika, 2019)

Seiring berjalannya waktu, kebutuhan fisiologis manusia akan semakin bertambah, salah satunya adalah kebutuhan dalam membeli rumah. Pengusaha properti akan berlomba-lomba membangun properti khususnya rumah untuk sarana investasi. Hal ini akan membuat harga rumah semakin hari semakin naik dengan daya beli masyarakat yang melonjak tinggi. Tentunya akan membuat masyarakat dalam membeli rumah berfikir apakah rumah yang ia beli akan mempunyai nilai keuntungan yang baik atau tidak. Dalam berinvestasi, tak lepas dengan menebak naik turunya harga agar tidak rugi dalam berinvestasi (Halimi et al., 2019). Harga yang tidak pasti dan tidak terprediksi ini membuat investor atau pembeli rumah membutuhkan sebuah sistem untuk memprediksikan harga rumah berdasarkan letak rumah tersebut.

Menurut Albani Musyafa (Musyafa, 2013) dalam penelitiannya yang berjudul "Komposisi Harga Jual Rumah Tinggal Layak Huni Di Yogyakarta" dengan menggunakan pembelajaran dokumen dan wawancara sebagai metode penelitiannya menyebutkan bahwa komponen harga rumah salah satunya berasal dari biaya lahan. Biaya lahan adalah biaya yang digunakan membeli lahan dimana harga lahan dipengaruhi oleh letak lahan tersebut. Hasil menunjukkan bahwa harga tanah memiliki kontribusi yang paling besar dalam menentukan harga jual rumah di Yogyakarta. Ini membuktikan bahwa semakin strategis letak lahan, akan semakin mahal harganya lahan maupun harga rumah yang dibangun diatasnya. Namun, pada penelitian yang berjudul "Case Base Reasoning Penentuan Harga Rumah dengan Menggunakan Metode Tversky" menujukkan bahwa harga rumah tidak hanya berdasarkan lokasi saja, namun juga ada faktor lain yang menentukan harganya. Salah satunya adalah akses transportasi menuju rumah tersebut (Hendra et al., 2017).

Pada penelitian lain berjudul "Building real estate valuation models with comparative approach through case-based reasoning" yang diteliti oleh I-Cheng Yeh, Tzu-Kuang Hsu (Yeh \& Hsu, 2018). Tujuannya adalah mengusulkan tentang penilaian real estate melalui pendekatan inovatif yang dapat menghitung koefisien koreksi. Penelitian ini menggunakan lima model regresi yaitu Linear Model, Quadratic Model, Logarithmic Model, Exponential Model, dan Exponential Growth Model. Didapatkan hasil pendekatan perbandingan kuantitatif dengan error hit rate $20 \%$ adalah 74,3 dengan skor RMSE 8,65.

Sehingga dalam penelitian ini, diusulkan penggunaan metode General Regression Neural Network menggunakan semua variabel yang ada dengan harapan prediksi yang didapatkan lebih akurat dan lebih luas. Metode Neural Network dengan algoritma General Regression Neural Network (GRNN) akan menghasilkan output yang diarahkan untuk mengikuti pola output data training. Implementasinya berupa sistem prediksi harga rumah diharapkan mampu memberikan informasi harga rumah yang sesuai dengan keadaan yang diharapkan. Penggunaan sistem khususnya pengusaha properti juga diharapkan mampu menghasilkan harga rumah yang dapat menjadi acuan dalam menawarkan rumahnya kepada pembeli atau menjadi acuan juga pembeli atau inverstor dalam menawar rumah tersebut.

\section{Metode Penelitian}

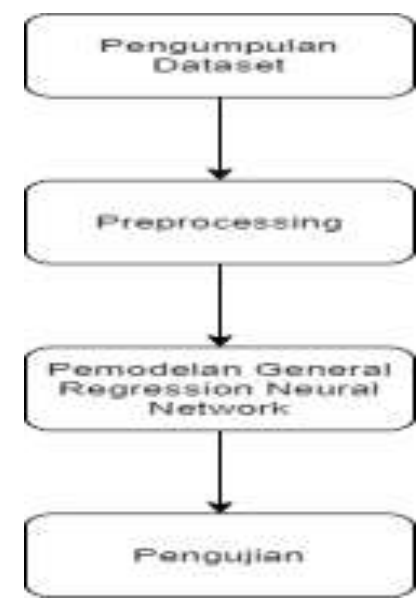

Gambar 1. Proses Penelitian 
Pada Gambar 1, dapat dilihat bahwa terdapat empat tahap dalam proses penelitian ini. Penelitian dimulai dengan pengumpulan dataset, lalu preprocessing data untuk menghilangkan data noise, dilanjutkan dengan proses pemodelan menggunakan General Regression Neural Network. Dan yang terakhir dilakukan beberapa uji akurasi sebagai evaluasi dari kinerja model. Untuk detail dari setiap tahap disajikan dibawah ini :

\section{Pengumpulan Dataset}

Pengumpulan dataset dengan cara pengunduhan pada UCI Machine Learning (https://archive.ics.uci.edu/ml/datasets/Real +estate+valuation+data+set). Karakteristik data terdiri dari 7 variabel. 6 variabel yang dijadikan variabel $X$ atau disebut variabel dependen dan 1 variabel yang dijadikan variabel $Y$ atau variabel independen.

\section{Pre-processing}

Data yang ada memiliki tipe data float dan integer. Diberikan pre-processing berupa proses converting semua data ke float untuk memudahkan dalam proses modeling dan juga rounding data untuk pembatasan berapa angka dibelakang koma. Normalisasi menggunakan MinMax Scaler pada variabel $X$. dilakukan juga. Dilakukan juga dropping terhadap beberapa variabel lokasi rumah berdasarkan Longitude dan Latitude yang nantinya akan merusak proses GRNN.

\section{General Regression Neural Network}

Algoritma yang dipakai pada penelitian ini adalah algoritma General Regression Neural Network (GRNN) yang dikembangkan oleh Specht pada tahun 1991 (Gholamrezaei \& Ghorbanian, 2007) merupakan salah satu model jaringan radial basis yang sering digunakan untuk pendekatan suatu fungsi. Dasar dari operasi GRNN secara esensial didasarkan pada regresi nonlinear (Marthasari et al., n.d.) (kernel) dimana estimasi dari nilai harapan output ditentukan oleh himpunan input-inputnya(Caraka et al., 2014). Struktur umum General Regression Neural Network digambarkan sebagai berikut

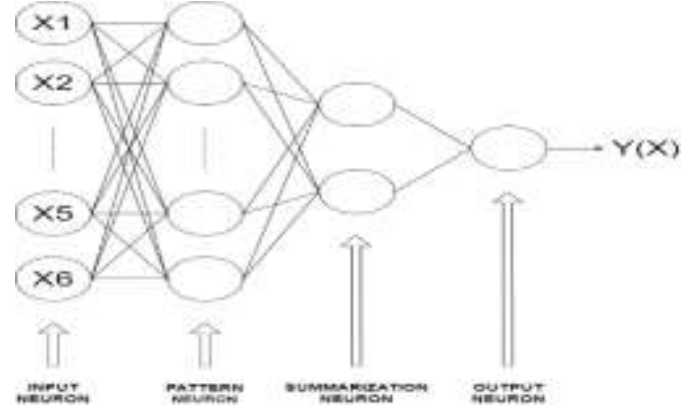

Gambar 2. Struktur Umum GRNN

General Regression Neural Network yang meniru cara kerja jaringan syaraf ini juga bekerja dengan cara meneruskan input dari layer sebelum-sebelumnya. Seperti halnya pada Gambar 2, algoritma ini membagi pemrosesan menjadi 4 layer, yakni (Düzgün, 2010) :

\section{Neuron Input}

Pada neuron input, input layer menerima vektor input berupa vektor $\mathbf{X}$ (di penelitian ini terdapat 6 vektor input) lalu didistribusikan setiap inputannya ke pattern layer.

\section{Neuron Pattern}

Pembangunan output $\theta$ terjadi pada tahap ini. Sehingga hasil yang didapat akan didistribusikan ke summation layer.

\section{Neuron Summation}

Pada neuron ini terdapat 2 neuron lagi, yakni Neuron Numerator dan Neuron Denominator. Pada neuron summation terjadi perhitungan yang didasarkan pada nilai $\theta$ dan $\mathrm{w}_{\mathrm{ij}}$ yang diperoleh berdasarkan pembelajaran melalui training.

\section{Neuron Output}

Pada layer imi dilakukan pembagian yang nilainya diperoleh dari hasil-hasil neuron summation.

\section{Pengujian}

Untuk menentukan akurasi prediksi, dan kinerja pemodelan GRNN, digunakan beberapa parameter evaluasi, diantaranya :

\section{Mean Square Error (MSE)}

MSE merupakan error yang dikuadratkan, semakin besar error semakin besar juga nilai MSE yang dihasilkan. Cara perhitungan MSE yang dikuadratkan ini membuat data outlier sangat memiliki sensitifitas. Formula MSE didefinisikan sebagai berikut (So et al., 2013)

$$
M S E=\frac{\sum\left(Y^{\prime}-Y\right)^{2}}{n}
$$




$$
\begin{array}{cl}
\text { Dengan keterangan : } \\
-\quad Y^{\prime}=\text { Predicted } \\
-\quad Y=\text { Actual } \\
-\quad n=\text { Jumlah Data }
\end{array}
$$

\section{Root Mean Square Error (RMSE)}

RMSE mengukur kuadratik dari rata-rata kesalahan atau error pada hasil actual dan predicted saat terjadi pemodelan. Formula RMSE didefinisikan sebagai berikut (Chai \& Draxler, 2014) :

$$
R M S E=\sqrt{\frac{\sum\left(Y^{\prime}-Y\right)^{2}}{n}}
$$

Dengan keterangan :

$$
\begin{array}{ll}
\text { - } & Y^{\prime}=\text { Predicted } \\
\text { - } & Y=\text { Actual } \\
\text { - } & n=\text { Jumlah Data }
\end{array}
$$

\section{Mean Absolute Error (MAE)}

MAE menentukan rata-rata kesalahan atau error pada hasil actual dan predicted saat pemodelan menggunakan GRNN. Didefinisikan sebagai berikut (Chai \& Draxler, 2014) :

$$
M A E=\frac{\sum\left|Y^{\prime}-Y\right|^{2}}{n}
$$

Dengan keterangan :

$$
\begin{aligned}
& \text { - } \quad Y^{\prime}=\text { Predicted } \\
& \text { - } \quad Y=\text { Actual } \\
& \text { - } \quad n=\text { Jumlah Data }
\end{aligned}
$$

\section{Hasil dan Pembahasan}

Data dalam penelitian ini menggunakan data sekunder yang diunduh dari UCI Machine Learning Repository yang diakses publik dengan judul "Real Estate Valuation Dataset". Pemilik dataset ini adalah Prof. I-Cheng Yeh dari Department of Civil Engineering, Tamkang University, Taiwan. Dataset ini berjumlah 414 record dan bersifat multivariate yang dikumpulkan dari Business Area Sindian District, New Taipei City, Taiwan pada tanggal 18 Agustus 2018.

Atribut dataset $(\mathrm{X})$ berjumlah 7 dengan karakteristik berupa bilangan integer dan real dengan penjelasan sebagai berikut:

\section{a. Transaction Date $\left(X_{1}\right)$}

Memuat tanggal dimana rumah itu dijual. Karena preprocessing dari data yang akan diolah menjadi regresi harus tidak dalam bentuk string, maka transaction date dirubah menjadi numerik dengan 4 digit 4 depan adalah tahun, dan 3 digit belakang adalah bulan ( 1 bulan $=83,33$ ). Contohnya sebagai berikut :
- 2013.250 adalah Maret 2013

- 2013.500 adalah Juni 2013

- 2012.667 adalah Agustus 2012

b. House Age $\left(X_{2}\right)$

Usia rumah dengan satuan tahun.

c. Distance to The Nearest MRT Station $\left(X_{3}\right)$ Jarak rumah dengan stasiun MRT terdekat. Satuannya adalah meter.

d. Number of Convenience Stores in the Living Circle on Foot $\left(X_{4}\right)$

Jumlah toko atau minimarket yang dekat dengan rumah.

e. Geographic Coordinate

Latitude $\left(X_{5}\right)$ dan Longitude $\left(X_{6}\right)$ sebagai letak geografis rumah.

Output (Y) yang pada dataset ini adalah harga rumah per unit area setelah dibagi 10.000 dalam satuan New Dollar Taiwan (\$NT) per ping. Sebagai contoh, nilai 37,9 pada atribut tersebut bermakna $37,9 \times$ $10.000=\$ N T 379.000 /$ ping. Dimana 1 ping sama dengan $3,3 \mathrm{~m}^{2}$, maka harga rumah tersebut adalah \$NT 114.848 per meter persegi.

Dataset dibagi menjadi dua bagian dengan 2/3 sampel (276 data) untuk training dataset dan $1 / 3$ sampel (138 data) untuk testing dataset.

Pemodelan dilakukan menggunakan General Regression Neural Network dalam beberapa langkah, yaitu :

\section{Plotting Data}

Langkah ini untuk mengetahui karakteristik data dan juga mengetahui bagaimana pola atau pengaruh salah satu variabel dependen $(X)$ terhadap variabel independen $(\mathrm{Y})$. Disajikan pada gambar dibawah ini.

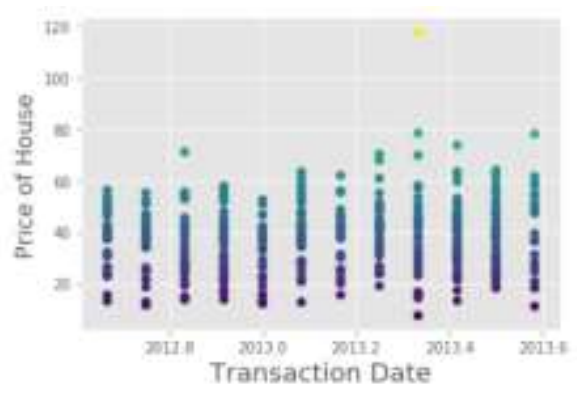

Gambar 3. Scatter Plot Harga Rumah dan Waktu Transaksi

Gambar 3 adalah plot yang menggunakan atribut harga rumah pada sumbu $y$ dan waktu transaksi yang diletakkan pada sumbu $x$. Pada pendahuluan disebutkan bahwa salah satu faktor yang mempengaruhi dalam 
pembelian rumah adalah harga (Widyasari \& Fifilia, 2009)(Azizah, 2019). Dari plot yang disajikan pada Gambar 3 dapat dilihat bagaimana hubungan atau relasi dari tanggal transaksi dengan harga rumah. Hal ini akan menjadi pertimbangan pembeli untuk melakukan transaksi karena pembeli akan memikirkan bagaimana harga rumah tersebut dengan pembelian sekarang dengan berjalannya waktu. Transaksi jual beli rumah yang berlokasi di Business Area Sindian District, New Taipei City, Taiwan memiliki harga yang relatif stabil dengan sedikit kenaikan dari waktu ke waktu. Pada penjelasan di atas dijelaskan bahwa harga rumah per unit area pada hasil prediksi adalah harga yang telah dilakukan tahap preprocessing. Hasil line plotting di atas harga rumah per unit area dibagi dengan \$NT 10.000. Namun harga rumah per unit area yang di maksudkan pada penelitian ini adalah semua harga rumah per unit area di kalikan \$NT 10.000 (Contohnya harga \$NT 20/Ping pada line plot adalah \$NT 20.000/Ping pada kenyataan harga rumah per unit areanya). Transaksi rumah pada tahun 2012 berjumlah 35 transaksi dengan 13 rumah berada dibawah harga \$NT 200.000/Ping. Artinya, $37 \%$ harga rumah di tahun 2012 berada di bawah \$NT 20.000/Ping dan 63\% berada di atas \$NT 200.000/Ping. Berbeda halnya dengan tahun 2013. Transaksi rumah pada tahun 2013 berjumlah 288 transaksi dengan 34 rumah berada dibawah harga \$NT $200.000 /$ Ping. Artinya, $13 \%$ harga rumah di tahun 2012 berada di bawah \$NT $200.000 /$ Ping dan $87 \%$ harga rumah berada di atas \$NT 200.000/Ping. Dari perbandingan kedua tahun diatas membuktikan bahwa terjadi kenaikan harga di setiap tahun dengan yang awalnya harga \$NT 200.000/Ping sebanyak $37 \%$ menjadi $13 \%$. Terdapat 3 warna utama pada plot yang disajikan pada Gambar 3. Pewarnaan dimulai dari warna ungu dengan semakin meninggi arah sumbu y menunjukkan perubahan warna ke hijau. Warna ungu menujukkan bahwa harga rumah dibawah \$NT 400.000 Ping. Warna hijau menujukkan bahwa harga rumah diatas \$NT 600.000 Ping. Warna diantara harga \$NT 400.000/Ping hingga \$NT 600.000/Ping menujukkan percampuran antara ungu dan hijau. Semakin hijau warna, semakin mendekati harga \$NT 600.000/Ping. Warna kuning menujukkan bahwa harga rumah diatas \$NT 1.000.000 Ping. Untuk harga \$NT $600.000 /$ Ping hingga \$NT 1.000.000/Ping diberikan percampuran antara warna hijau dan kuning. Semakin kuning warnanya, semakin mendekati \$NT 1.000.000/Ping.

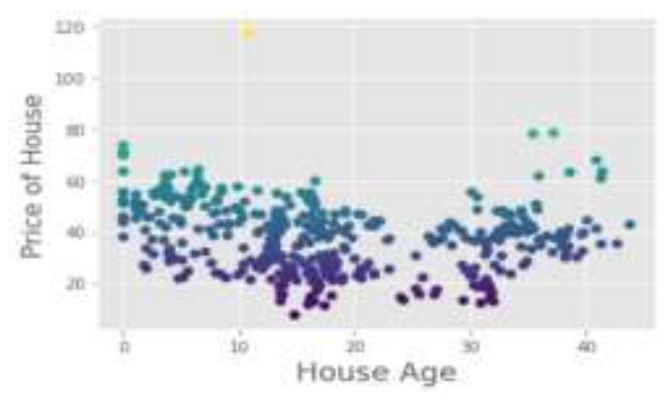

Gambar 4. Scatter Plot Harga Rumah dan Usia Rumah

Pada Gambar 4 diberikan penggambaran tentang hubungan umur rumah dengan harga rumah dengan scatter plot. Penyajian plot dengan atribut harga dan umur rumah bertujuan untuk memudahkan dalam menganalisa hubungan seperti bagaimana harga rumah dengan usia rumah yang lama, apakah rumah semakin baru akan semakin mahal atau tidak. Gambar 4 menunjukkan bahwa rentang umur rumah adalah dari 0 tahun hingga 40 tahun dengan beberapa rumah yang memiliki umur lebih dari 40 tahun. Harga berkisar berada di bawah \$NT 800.000 Ping, meskipun terdapat satu rumah yang jauh berada di atas $\$ N T 800.000$ Ping. Disimpulkan dari scatter plot di atas bahwa tidak ada hubungannya antara harga rumah dengan usia rumah. Ini dibuktikan dengan semakin acaknya titik plot yang ada. Terdapat rumah dengan usia 30 tahun, namun harganya \$NT 600.000 Ping dan ada juga yang harganya bahkan di bawah \$NT 200.000 Ping.

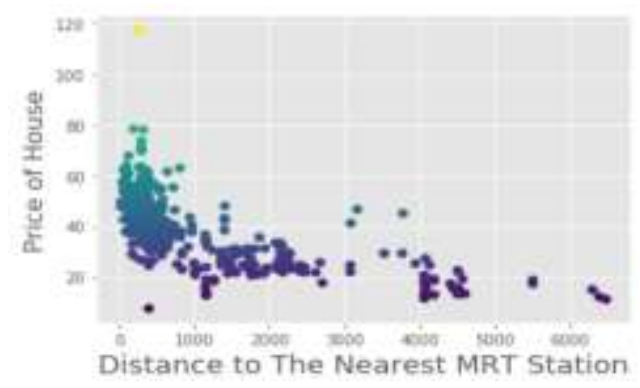

Gambar 5. Scatter Plot Harga Rumah dan Jarak Rumah ke Stasiun MRT

Gambar 5 menggambarkan tentang penyebaran plot dengan atribut harga pada sumbu $y$ dan jarak rumah dengan stasiun MRT sebagai sumbu $x$. Dapat dilihat pada 
penyebaran titik diatas, titik-titik plot banyak berkumpul pada jarak 0 sampai 1000 meter dengan warna hijau yang mendominasi. Dengan demikian, dapat disimpulkan bahwa rata-rata rumah berada pada jarak yang tidak lebih dari 1000 meter dari stasiun MRT. Tentunya disusul dengan harga yang semakin mahal. Kesimpulan diatas dapat digunakan oleh pembeli sebagai bahan pertimbangan dalam membeli rumah dengan tambahan budget yang tidak sedikit jika ingin memiliki rumah dekat dengan stasiun MRT.

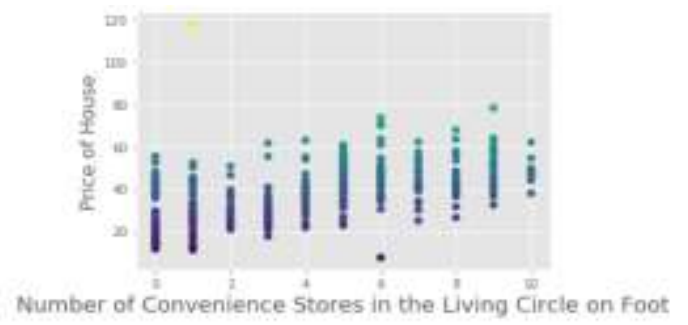

Gambar 6. Scatter Plot Harga Rumah dan Banyaknya Toko yang Dekat dengan Rumah

Pada Gambar 6, ditunjukkan plotting data dengan atribut harga dan jumlah toko yang dekat dengan rumah. Plot ini disajikan dengan tujuan agar terlihat bagaimana hubungan diantara harga dan jumlah toko yang dekat dengan rumah. Dan tentunya hal itu akan menjadi pertimbangan dalam melakukan transaksi pembelian rumah. Titiktitik menyebar pada jumlah toko 0 sampai 10 toko dengan warna yang terdiri dari ungu, hijau, dan kuning. Namun, titik bergerak semakin tinggi ke arah sumbu y saat jumlah toko semakin banyak. Ini membuktikan bahwa semakin banyak toko yang dekat dengan rumah, semakin mahal harga yang ditawarkan.

Plotting data diatas bertujuan untuk memberikan gambaran tentang bagimana penyebaran data, bagaimana kondisi data yang ada sehingga pembaca mudah dalam mengerti data yang ada. Dari proses plotting semua atribut diatas dengan atribut harga menghasilkan kesimpulan sebagai berikut :

i. Harga rumah di kawasan Business Area Sindian District, New Taipei City, Taiwan cenderung stabil dan memiliki rata-rata harga di bawah \$NT 800.000 Ping.

ii. Tidak ada hubungan harga rumah dengan umur rumah.

iii. Semakin dekat jarak rumah dengan stasiun MRT, semakin mahal harga rumah. iv. Semakin banyak jumlah toko yang ada didekat rumah, semakin mahal harga rumah tersebut.

\section{Pemodelan General Regression Neural Network}

Pemodelan diawali dengan splitting data training yang digunakan untuk prediksi. Digunakan 4 variabel sebagai variabel dependen yaitu waktu transaksi (X1), usia rumah $(X 2)$, jarak rumah dengan stasiun MRT (X3), jumlah toko yang dekat dengan rumah (X4). Sebagai target variabel atau variabel independen yaitu harga rumah setiap luas tertentu. Splitting data menggunakan library train test split dimana data yang didapatkan sebanyak $20 \%$ dari jumlah data keseluruhan yaitu 83 data. Preprocessing menggunakan MinMax Scaler untuk proses normalisasi variabel dependen. Prediksi dilakukan dengan menggunakan GRNN dengan hasil yang dapat dilihat pada Tabel 1 dibawah ini.

Tabel 1. Tabel Sampel Hasil Prediksi GRRN

\begin{tabular}{ccc}
\hline No & Actual & Predicted \\
\hline 1 & 38,4 & 34,4 \\
2 & 27,7 & 29,7 \\
3 & 42,3 & 36,2 \\
4 & 25,6 & 26,6 \\
5 & 19,1 & 29,0 \\
\hline
\end{tabular}

Hasil pada prediksi menggunakan GRNN ini digambarkan dengan visualisasi menggunakan line plot dengan warna hijau sebagai harga actual dan warna merah sebagai harga predicted.

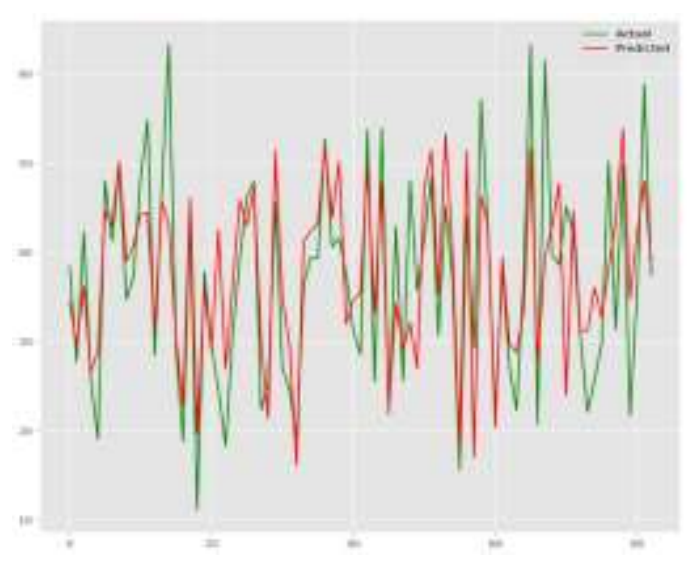

Gambar 7. Visualisasi Hasil Prediksi Menggunakan Line Plot 
Pada hasil line plot Gambar 7, ditunjukkan bahwa prediksi yang dihasilkan, tidak ada data predicted yang sesuai dengan data actual yang ada. Hal ini terlihat jelas pada hasil dari visualisasi yang dilakukan. Model GRNN mampu memberikan prediksi yang mirip, meskipun titik actual dan predicted yang diperoleh pada line plot tergolong jauh. Namun, saat penggambaran titik data actual yang berada pada titik tertentu lalu selanjutnya pada titik yang lebih tinggi, GRNN mampu memprediksi hal itu. Sehingga dapat disimpulan bahwa GRNN mampu memprediksi dengan baik.

\section{Pengujian}

Untuk menguji akurasi dan kinerja dari pemodelam GRNN, digunakan evaluasi MSE, RMSE dan MAE. Didapatkan hasil sebagai berikut :

Tabel 2. Tabel Uji Akurasi dan Kinerja Model

\begin{tabular}{ccc}
\hline No & Evaluasi & Hasil \\
\hline 1 & MSE & 58,61 \\
2 & RMSE & 7,66 \\
3 & MAE & 5,99 \\
\hline
\end{tabular}

Karena dibutuhkan pembanding dalam menentukan baik atau tidaknya model GRNN, maka perbandingan dilakukan dengan melihat RMSE. Dilakukan perbandingan penelitian dengan menggunakan penelitian yang sebelumnya dilakukan oleh I-Cheng Yeh dan Tzu-Kuang Hsu dengan judul "Building real estate valuation models with comparative approach through case-based reasoning" (Yeh \& Hsu, 2018). Skor RMSE yang dihasilkan adalah 8,65. Dengan hasil uji akurasi GRNN dengan RMSE sebesar 7,66, maka General Regression Neural Network ini lebih baik dibandingkan dengan model yang dipakai pada penelitian pembanding.

\section{Kesimpulan}

Prediksi menggunakan model General Regression Neural Network merupakan regresi dengan dasar non linear. Dengan data test sebanyak $20 \%$ dari data keseluruhan menunjukkan bahwa prediksi menggunakan GRNN mampu menghasilkan akurasi prediksi yang cukup baik.

\section{Referensi}

Caraka, R. E., Yasin, H., \& Prahutama, A. (2014). Prediksi Produksi Gas Bumi dengan General Regression Neural Network (GRNN). Prosiding Seminar Nasional Statistika IV, 270-277. https://doi.org/10.13140/RG.2.1.2499.8 807

Chai, T., Draxler, R. R., \& Prediction, C. (2014). Root mean square error (RMSE ) or mean absolute error (MAE )? Arguments against avoiding RMSE in the literature. 2005, 1247-1250. https://doi.org/10.5194/gmd-7-12472014

Chamid, A. A. (2016). Penerapan Metode Topsis Untuk Menentukan Prioritas Kondisi Rumah. J Simetris, 7(2), 537544.

https://doi.org/10.24176/simet.v7i2.765

Düzgün, R. (2010). Generalized regression neural networks for inflation forecasting. International Research Journal of Finance and Economics.

Gholamrezaei, M., \& Ghorbanian, K. (2007). Rotated general regression neural network. IEEE International Conference on Neural Networks - Conference Proceedings, 2(6), 1959-1964. https://doi.org/10.1109/IJCNN.2007.43 71258

Azizah, L. N,. (2019). Analisis Pengaruh Harga, Pendapatan, Lokasi dan Fasilitas Terhadap Permintaan Rumah Subsidi. Media Mahardika, 17(3), 444450.

http://dx.doi.org/10.29062/mahardika.v $17 \mathrm{i} 3.101$.

Hendra, Tursina, \& Nyoto, R. D. (2017). Case Base Reasoning Penentuan Harga Rumah d engan Menggunakan Metode Tversky ( Studi Kasus : Kota Pontianak ). Jurnal Sistem Dan Teknologi Informasi (JUSTIN), 5(2), 75-79.

Mahendra, I., \& Putri, P. K. (2019). Implementasi Metode Analytical Hierarchy Process (Ahp) Dalam Sistem Pendukung Keputusan Pembelian Rumah Di Kota Tangerang. Jurnal Teknoinfo, 13(1), 36. https://doi.org/10.33365/jti.v13i1.238

Marthasari, G. I., \& Djunaidy, A. (2014). Optimasi Data Latih Menggunakan Algoritma Genetika Untuk Peramalan Harga Emas Berbasis Generalized Regression Neural Network. Jurnal SISFO, $5(1)$, 
https://doi.org/10.24089/j.sisfo.2014.03 .014

Musyafa, A. (2013). Komposisi Harga Jual Rumah Tinggal Layak Huni Di Yogyakarta (Studi Kasus Pembangunan Rumah Tipe 90/115 di Luar Kompleks Perumahan) (004K). Konferensi Nasional Teknik Sipil 7 (KoNTekS 7), K-7 - K-12.

Halimi, I., Azhar, Y. \& Marthasari, G. I. (2019). Prediksi Harga Emas Menggunakan Univariate Convolutional Neural Network. Repositor, 1(2), 105-116. https://doi.org/10.22219/repositor.v1i2. 612

So, H. C., Chan, Y. T., Ho, K. C., \& Chen, Y. (2013). Simple Formulas for Bias and Mean Square Error Computation. June. IEEE Signal Processing Magazine, 162-165.

https://doi.org/10.1109/MSP.2013.2254
600

Utamaningsih, A., Monika, G. \& Yenika (2019). Motivasi Kerja Karyawan dalam Kajian Teori Kebutuhan Maslow. J. Ilmiah Poli Bisnis, 11(2), 133-142. https://doi.org/10.30630/jipb.11.No.\%2 02.252

Widyasari, S., \& Fifilia, E. T. (2009). Analisis Pengaruh Produk, Harga, Promosi dan Lokasi Terhadap Keputusan Pembelian Rumah ( Studi pada Perumahan Graha Estetika Semarang ). Jurnal Telaah Manajemen, 6(2), 159-169.

Yeh, I. C., \& Hsu, T. K. (2018). Building real estate valuation models with comparative approach through casebased reasoning. Applied Soft Computing Journal, 65, 260-271. https://doi.org/10.1016/j.asoc.2018.01. 029 